\title{
Anodisation of Aluminium Alloys by Micro-Capillary Technique as a Tool for Reliable, Cost-Efficient, and Quick Process Parameter Determination
}

\author{
Daniela Nickel, ${ }^{1,2}$ Dagmar Dietrich, ${ }^{1}$ Roy Morgenstern, ${ }^{1}$ Ingolf Scharf, ${ }^{1}$ \\ Harry Podlesak, ${ }^{3}$ and Thomas Lampke ${ }^{1}$ \\ ${ }^{1}$ Materials and Surface Engineering Group, Technische Universität Chemnitz, 09107 Chemnitz, Germany \\ ${ }^{2}$ Center of Engineering Materials, State Materials Testing Institute Darmstadt (MPA), Chair and Institute for Materials Science (IfW), \\ Technische Universität Darmstadt, 64283 Darmstadt, Germany \\ ${ }^{3}$ Composite Materials Group, Technische Universität Chemnitz, 09107 Chemnitz, Germany
}

Correspondence should be addressed to Dagmar Dietrich; dagmar.dietrich@mb.tu-chemnitz.de

Received 20 September 2015; Revised 25 January 2016; Accepted 7 February 2016

Academic Editor: Gianluca Percoco

Copyright (c) 2016 Daniela Nickel et al. This is an open access article distributed under the Creative Commons Attribution License, which permits unrestricted use, distribution, and reproduction in any medium, provided the original work is properly cited.

Anodisation is essential for improving surface properties of aluminium alloys and composites regarding wear and corrosion behaviour. Optimisation of the anodising process depends on microstructural constituents contained in aluminium alloys and represents a key task, consisting of the control of process parameters and electrolyte formulation. We applied the micro-capillary technique known from corrosion studies and modified it to form anodic aluminium oxide films on high-strength aluminium alloys in comparison to pure aluminium in sulphuric acid. A glass capillary with an opening of $800 \mu \mathrm{m}$ in diameter was utilized. Corresponding electrochemical measurements during potentiodynamic and potentiostatic anodisation revealed anodic current responses similar to conventional anodisation. The measurement of film thickness was adapted to the thin anodised spots using ellipsometry and energy dispersive X-ray analysis. Cross sections prepared by focused ion beam milling confirm the thickness results and show the behaviour of intermetallic phases depending on the anodising potential. Consequently, micro-capillary anodising proved to be an effective tool for developing appropriate anodisation conditions for aluminium alloys and composites because it allows quick variation of electrolyte composition by applying low electrolyte volumes and rapid film formation due to short process durations at small areas and more flexible variation of process parameters due to the used set-up.

\section{Introduction}

The generation of microstructural constituents in tailor-made aluminium based materials resulted in substantial progress achieved in development and application of this material group. Kinds of microstructural constituents can be dislocation arrangements and grain boundaries (high- and lowangle boundaries), solid solution formation, and arrangements of intermetallic compound (IC) particles of varying sizes. As regards the latter, these second-phase particles in aluminium alloys affect the material behaviour depending on their size: constituent particles of fairly large size, dispersoids of mostly intermediate size or fine-scaled hardening precipitates. For example, the dominant constituent phase in
AlZn5.5MgCu alloys is $\mathrm{Al}_{7} \mathrm{Cu}_{2} \mathrm{Fe}$; additionally existent are $(\mathrm{Al}, \mathrm{Cu})_{6}(\mathrm{Fe}, \mathrm{Cu}) ; \mathrm{Al}_{6} \mathrm{Fe} ; \mathrm{Mg}_{2} \mathrm{Si}, \alpha-\mathrm{Al}_{12} \mathrm{Fe}_{3} \mathrm{Si}$, and $\mathrm{SiO}_{2}$ [1]. Most of the second-phase particles possess complex chemistry, crystal structure, and morphology. Dispersoids in the $\mathrm{AlZn} 5.5 \mathrm{MgCu}$ alloy show a variety of rod-like, triangular, or globular shapes [1]. The general properties of this alloy are mainly determined by equilibrium phases like $\mathrm{MgZn}_{2}(\mathrm{M}-$ phase, $\eta$ phase), $\mathrm{Al}_{2} \mathrm{Mg}_{3} \mathrm{Zn}_{3}$ (T-phase), and $\mathrm{Al}_{2} \mathrm{CuMg}$ (Sphase). Responsible for high strength are the $\eta$ phase, its precursors GP zones, and intermediate precipitates ( $\eta^{\prime}$ phase). The transition phases are semi-coherent and mostly located inside the matrix grains on dislocations and low-angle boundaries. The incoherent equilibrium phases nucleate on highangle boundaries and in the grain interior [2]. The dispersoids 
TABLE 1: Chemical composition of the studied materials according to the specification of the producer.

\begin{tabular}{lccccccccc}
\hline Alloy & $\mathrm{Si}$ (wt.\%) & $\mathrm{Fe}$ (wt.\%) & $\mathrm{Cu}$ (wt.\%) & $\mathrm{Mn}$ (wt.\%) & $\mathrm{Mg}$ (wt.\%) & $\mathrm{Cr}$ (wt.\%) & Zn (wt.\%) & Ti (wt.\%) & $\mathrm{Al}$ \\
\hline Al 5N & 0.00079 & 0.00098 & $<0.0002$ & 0.00004 & 0.00103 & 0.000059 & 0 & 0.000098 & Bal. \\
1050 & $<0.25$ & $<0.4$ & $<0.05$ & $<0.05$ & $0-0.05$ & $<0.03$ & $<0.07$ & $<0.05$ & Bal. \\
2024 & 0.50 & 0.50 & $3.5-4.9$ & $0.3-0.9$ & $1.2-1.8$ & 0.10 & 0.25 & 0.15 & Bal. \\
7075 & 0.40 & 0.50 & $1.2-2.0$ & 0.30 & $2.1-2.9$ & $0.18-0.28$ & $5.1-6.1$ & 0.20 & Bal. \\
\hline
\end{tabular}

$\mathrm{Al}_{2} \mathrm{Mg}_{3} \mathrm{Zn}_{3}$ and $\mathrm{Al}_{2} \mathrm{CuMg}$ are known to affect hot workability and fracture properties. Compared to T561 temper, $\eta^{\prime}$ phase and $\eta$ phase are coarsened by artificial overaging in temper T73, which is beneficial to increase the resistance to stresscorrosion cracking [2-4].

Automotive and aerospace applications require enhanced corrosion resistance, improved tribological properties, or a simply improved decorative appearance. This is usually accomplished by the formation of an anodised aluminium oxide $(\mathrm{AAO})$ due to the conversion of the surface region of the aluminium alloy [5]. AAO films on pure aluminium are fairly homogeneous showing hexagonal arranged pores perpendicular to the surface which results from the dynamic equilibrium between film growth at the metal/oxide interface and field-assisted dissolution at the pore bases [6]. In contrast, the microstructure and the resulting properties of AAO films formed on aluminium alloys are severely influenced due to the conversion of solid solutions and the behaviour of second phases during anodisation [7, 8]. In particular, anodising of copper-containing alloys is remarkably limited due to inefficient film growth and enhanced porosity of the produced AAO film $[9,10]$. Dissolution of second-phase particles results in voids and gas-pockets $[11,12]$. Second-phase particles with low oxidation rates can be incorporated into the film because of the faster oxidation of the surrounding matrix [12-14]. This observation was similarly made for AAO films formed on aluminium matrix composites (AMC) with alumina or silicon carbide particles $[15,16]$. Anodic oxidation rates of a variety of ICs have been examined in relation to that of the matrix [17]. Recent studies considered the detailed processes occurring at ICs by simultaneously recording the electrochemical data. Film formation was performed by either potentiostatic (constant potential), galvanostatic (constant current density), or potentiodynamic anodisation (increasing potential with defined rate). The current density response during potentiodynamic anodisation and the time-voltage response during galvanostatic anodisation were discussed with regard to several commercial alloys, different electrolytes, and occurring growth stages during AAO film formation [12-14]. Potentiodynamic anodising was proposed as an efficient tool for the development of appropriate anodising parameters since it provides a rapid characterisation of the complex electrolyte/alloy behaviour over a wide potential range [18]. Such studies comprise the application of newly designed electrolyte formulations for anodising of aluminium alloys and aluminium matrix composites. Nevertheless, using conventional anodising for this task necessitates the application of large electrolyte volumes in the scale of several litres with the disadvantage of high expenses for procurement and disposal.
The aim of this work is to transfer the micro-capillary technique known from local corrosion research [19-23] to local anodising studies. Recently, this technique was sophisticated by developing multichannel arrangements for improving scanning droplet cell microscopy [24]. We applied the micro-capillary technique on pure aluminium and three commercial aluminium alloys. Sulphuric acid was chosen as a common electrolyte to provide the comparison to conventional anodising and to demonstrate the feasibility of the technique. The simultaneous electrochemical characterisation during initiation and progress of the film growth has been studied and correlated with microstructural features, in particular with the behaviour of second-phase particles and the development of the film thickness on the example of the high-strength and stress-corrosion resistant alloy EN AW7075 in T73 condition that is artificially aged for providing stress-corrosion resistance. Film thickness measurement was adapted to thin and small AAO areas. Finally, a discussion on potentials and limitations of the presented method is given.

\section{Materials and Methods}

Pure aluminium (Al 5 N, Hydro Aluminium Rolled Products $\mathrm{GmbH}$ ) and three commercial aluminium alloys in extruded condition and the given temper (EN AW-1050, EN AW 2024 T4, EN AW-7075 T651, and T73; for chemical composition see Table 1) were used. Samples were etched in $3 \mathrm{wt} . \%$ sodium hydroxide $(\mathrm{NaOH})$ for $60 \mathrm{~s}$ at $50^{\circ} \mathrm{C}$ and desmutted in 30 vol. $\%$ nitric acid $\left(\mathrm{HNO}_{3}\right)$ for $30 \mathrm{~s}$ at room temperature. After anodising, the surface was rinsed carefully with deionized water and ethanol.

The samples were anodised in $0.4 \mathrm{M}$ sulphuric acid $\left(\mathrm{H}_{2} \mathrm{SO}_{4}\right)$ at room temperature $(22 \pm 0.5){ }^{\circ} \mathrm{C}$ using a micro corrosion cell (Swiss Microcell System) based on a glass capillary technique. Parts of the three-electrode set-up are a glass capillary with a ground tip of $800 \mu \mathrm{m}$ in diameter and a seal of a silicone rubber layer to prevent leakage acting as anodising electrode, a $0.5 \mathrm{~mm}$ platinum wire acting as counter electrode, and a silver/silver chloride (3 $\mathrm{M} \mathrm{KCl)} \mathrm{elec-}$ trode acting as reference electrode. An exact positioning of the capillary was permitted by mounting the electrode set-up at the nosepiece of an optical microscope (OM) and fixing the samples at the stage of the OM. A detailed description of the microcell system has been published elsewhere [23] [BÖH95]. Each test was performed at least twice. Anodising was accompanied by micro-electrochemical measurements using a high precision voltage source (DIGISTANT Model 4462, Burster Präzisionsmesstechnik), a potentiostat (IMP83 PCT-BC, Jaissle Elektronik), and a digital multimeter (Model 
2000, Keithley Instruments) providing a noiseless data acquisition with a rate of $9.1 \mathrm{~Hz}$ matching one point every $1.85 \mathrm{mV}$ during the used sweep rate. Potentiodynamic anodising was done from the open circuit potential to $10 \mathrm{~V}$ at a sweep rate of $17 \mathrm{mV} / \mathrm{s}$. Potentiostatic anodising was performed for $600 \mathrm{~s}$ using potentials between $0.3 \mathrm{~V}$ and $10 \mathrm{~V}$. For comparison with conventional anodising, a three-electrode corrosion cell with the working electrode (exposed area $10 \mathrm{~mm}$ in diameter), Pt counter electrode, and $\mathrm{Ag} / \mathrm{AgCl}(3 \mathrm{M} \mathrm{KCl})$ reference electrode was used. Macro-scaled anodising was performed in stirred electrolyte at controlled temperature $(22 \pm 0.5){ }^{\circ} \mathrm{C}$ at an anodising potential of $10 \mathrm{~V}$ for $1200 \mathrm{~s}$ and $3600 \mathrm{~s}$. The ratio of electrolyte volume to sample surface area was around $3 \mathrm{~mL} / \mathrm{mm}^{2}$ in the micro-capillary set-up and $50 \mathrm{~mL} / \mathrm{mm}^{2}$ in the macroscopic set-up. All potentials designated in this paper refer to the $\mathrm{Ag} / \mathrm{AgCl}(3 \mathrm{M} \mathrm{KCl})$ electrode if not indicated differently.

Microstructural studies were done using a scanning electron microscope (SEM, Zeiss NEON 40EsB crossbeam) equipped with a focused ion beam mill (FIB, Orsay) and an energy dispersive X-ray spectrometer (EDS, EDAX). Alloys were examined by low-voltage scanning transmission electron microscopy (LV-STEM) at $30 \mathrm{kV}$ in combination with EDS. Electron transparent samples were prepared by grinding, electropolishing, and finally ion-polishing on both sides using $3 \mathrm{kV}$ Ar ions with $6^{\circ}$ incidence angle. AAO films were studied by scanning electron microscopy. Surface imaging with secondary electrons (SE) was done without carbon coating at $2 \mathrm{kV}$ using Everhart-Thornley detector. EDS spectra were acquired at $5 \mathrm{kV}$. Cross sections of the $800 \mu \mathrm{m}$ circular AAO film areas were prepared by focused ion beam (FIB) milling after deposition of a tungsten protective coating. $30 \mathrm{kV} \mathrm{Ga}$ ions with a current of $10 \mathrm{pA}$ for the last polishing step were used. Imaging of the cross sections was accomplished at $3 \mathrm{kV}$ using the InLens detector of the SEM.

Ellipsometry data for film thickness and porosity evaluation were collected with a rotating analyser ellipsometer (M-2000, J.A. Woollam Co.) in the spectral range from 1690 to $245 \mathrm{~nm}$ with incidence angles of $45,50,55$, and $60^{\circ}$. The diameter of the polarised light beam was $1 \mathrm{~mm}$ resulting in an elliptical measuring area comparable to the anodised area. Modelling, regression analysis and parameter fit was done using the software CompleteEASE (J.A. Woollam Co). Bspline was used as polynomial function for the substrate and an effective medium approximation for the films. Modelling of the pores in the layer was done by a Cauchy layer of (100x) vol\% alumina and $\mathrm{x}$ vol\% air.

\section{Results and Discussion}

Potentiodynamic linear polarisation curves were recorded during anodisation in sulphuric acid in a micro-capillary cell arrangement (Figure 1). The curves of the alloys consist of four stages: (i) starting with a current peak around $0 \mathrm{~V}$ which is most pronounced for EN AW-2024; (ii) followed by monotone rising up to $3 \mathrm{~V}$, (iii) a shallow peak between 3 and $6 \mathrm{~V}$ for EN AW-2024 and correspondingly between 4 and 9.5 V for EN AW-7075; (iv) further rising with different slopes

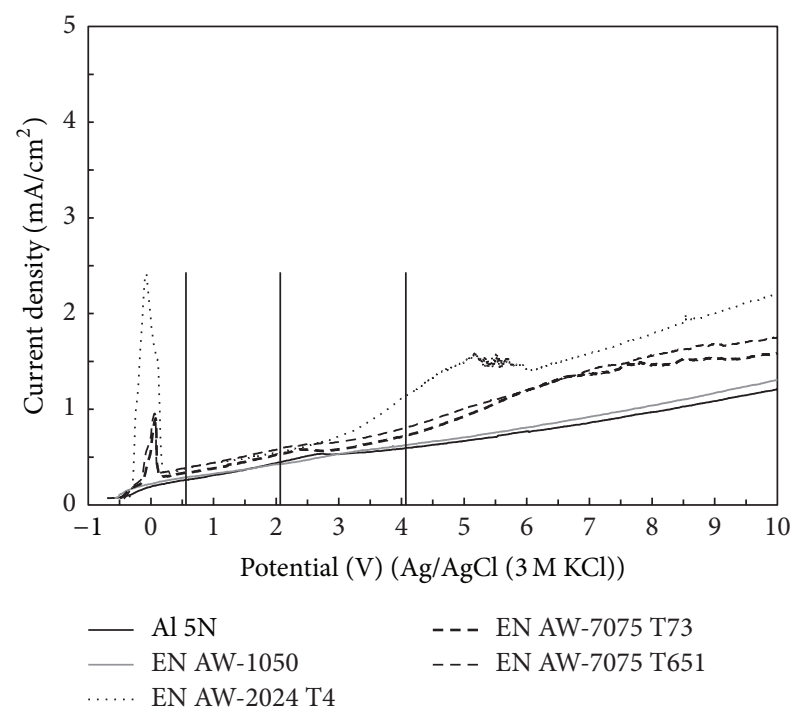

Figure 1: $I / V$ behaviour of Al $5 \mathrm{~N}, \mathrm{EN}$ AW-1050, EN AW-2024 T4, EN AW-7075 T73, and EN AW-7075 T651 during potentiodynamic anodising in $0.4 \mathrm{M}$ sulphuric acid using the micro-capillary technique; vertical lines mark the potentials selected for potentiostatic anodising (as shown in Figures 4 and 5).

depending on the material. Different temper states of the alloy EN AW-7075 slightly affect the overall current density level and the peak width in (i).

As discussed in the Introduction, the alloy EN AW-7075 was selected for further experiments since it includes a large variety of $\mathrm{Zn}, \mathrm{Mg}, \mathrm{Cu}, \mathrm{Fe}$, and Si containing IC particles with high influence on the microstructure of the AAO film. The film after potentiodynamic anodisation is characterised by numerous voids due to the oxidation and dissolution of second-phase particles. Using secondary electrons, the arrangement of the hardening IC particles in the alloy is shown on the alloy surface before anodisation (Figure 2(a)). A cross section of the alloy with the AAO film on top is shown in Figure 2(c) after. Using backscattered electrons, grain boundaries of partially elongated grains of the alloy parallel to the extrusion direction are visible due to the orientation contrast. The coarsened hardening precipitates are located on the grain boundaries; finer intermetallic particles are located inside the grains. A rather corresponding arrangement of voids in the AAO film can be observed in Figure 2(b) in planar view. Larger voids seem to mirror former grain boundaries and finer voids are located inside the thus bordered areas. A large constituent particle appears mostly unchanged embedded in the film. A detailed image of the film morphology at higher magnification (Figure 2(d)) clearly reveals shape and size of the voids originating from the IC particles and the pore structure in between, respectively. The pores originally straight perpendicular directed to the alloy surface show a frequent change of the direction as a result of the wavy interface which evolves between the alloy and the anodised film. However, the pore structure is not as complex as it develops on EN AW-2024. The branching of pores is associated with copper enrichment during anodisation of the alloys which is delayed 


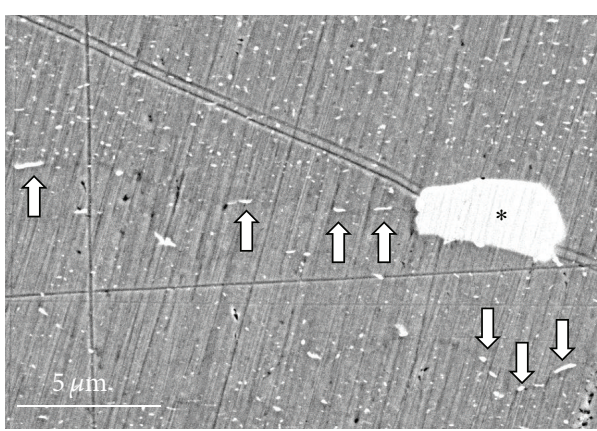

(a)

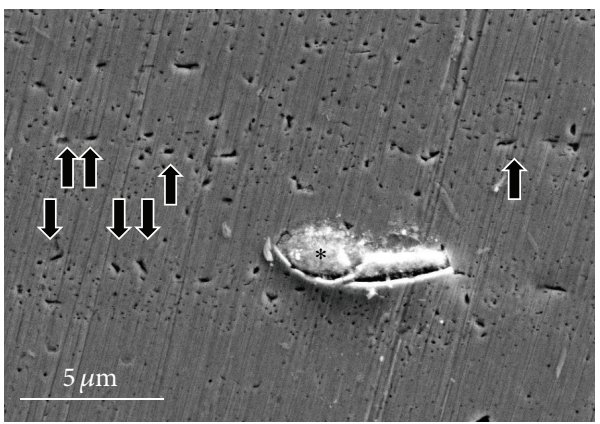

(c)

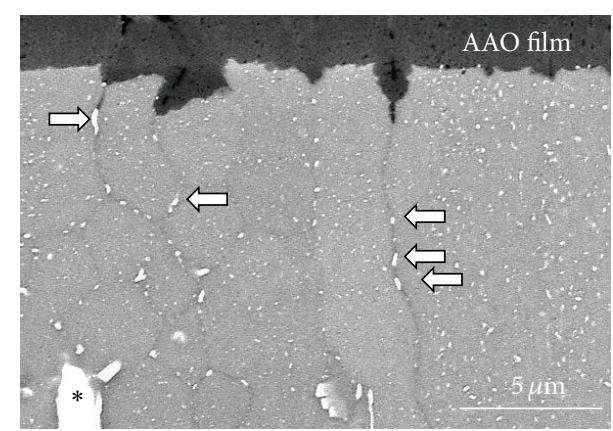

(b)

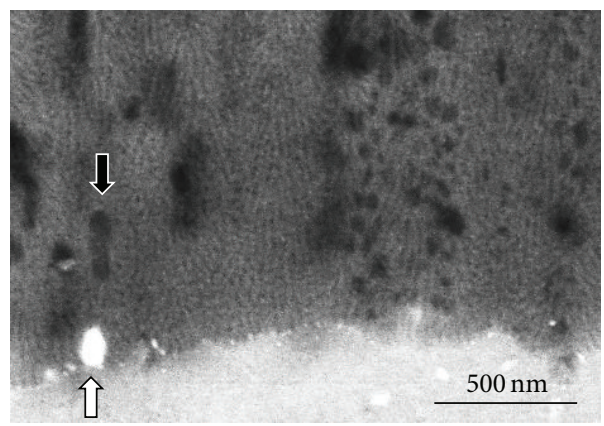

(d)

FIgURE 2: The microstructure of EN AW-7075 T73 in (a) planar view and (b) cross section (with the AAO film on top), and the AAO film formed by potentiodynamic anodising of this alloy in $0.4 \mathrm{M}$ sulphuric acid in (c) planar view and (d) cross section showing the behaviour of coarse constituent particles resistant to anodising (marked by asterisks) and IC particles along grain boundaries (some ones are marked by white arrows) and in the grain interior resulting in voids in the AAO film (some ones are marked by black arrows).

due to the lower concentration of copper in EN AW-7075 and thus permits the development of straight pores to a larger extent.

TEM imaging of the grain interior of the alloy (Figure 3(a)) reveals a variety of dispersoids. Additionally, uniformly arranged hardening precipitates are shown. The grain boundary decorating particles were confirmed as $\eta$ phase $\left(\mathrm{MgZn}_{2}\right)$. EDS analyses verified also the existence of a range of other ICs: $\mathrm{Mg}_{2} \mathrm{Si}, \mathrm{MgZn}_{2}, \mathrm{Mg}_{32} \mathrm{Zn}_{49}, \mathrm{Mg}(\mathrm{AlCu})$, $\mathrm{Al}_{2} \mathrm{CuMg}$, and $\mathrm{Al}_{7} \mathrm{Cu}_{2} \mathrm{Fe}$. However, it should be noted that it was not possible to identify all particles exactly by EDS analysis due to the excitation volume which mostly comprises the matrix too. Moreover, it was not possible to make a certain correlation between shape and stoichiometry. The AAO film is shown in the same magnification in Figure 3(b) giving evidence of a multitude of pore mouths typical for AAO films, larger voids as a result of complete dissolution of IC particles and embedded particles probably originating from chemically transformed ICs.

Potentiostatic anodisation experiments using the capillary technique were conducted to get a deeper insight into the film formation and the behaviour of second-phase particles in EN AW-7075. Four anodisation potentials were selected as indicated in Figure 1. The corresponding current density response as a function of the duration of anodisation is shown for anodising small spots under the micro-capillary (Figure 4) and for the first $600 \mathrm{~s}$ of the larger areas $10 \mathrm{~mm}$ in diameter (Figure 5). Both experiments show a fairly similar behaviour. Differences in the absolute current density are noticed only for both lower potentials which is attributed to the influence of electrolyte alteration in the micro-capillary set-up without a continuous electrolyte flow and stirring. The overall behaviour shows increasing current density with increasing anodising potential. Generally, an initial current density drop is followed by a plateau. This behaviour is associated with an uneven film growth in the initiation phase followed by a rather uniform thickening in the steady current density region. Curioni et al. [13] found a similar but more pronounced transient region between the initial current density drop and the plateau region for the alloy 2024-T3 above $3 \mathrm{~V}$ (SCE).

The AAO films formed by potentiostatic anodisation are shown in Figure 6. Their circular areas correspond to the capillary opening. The spots show distinct interference colours with regard to thickness of the formed films as expected from the variation of the applied charge transfer. Naturally, this is the case for all studied alloys as well as for pure aluminium. According to Faraday's law, the theoretically achievable thickness of alumina films on pure aluminium was calculated first. Several methods were used to determine the actual thickness on the alloy because the measurement of submicrometre films at fairly small areas with inhomogeneous composition and varying porosity is a nontrivial task. An estimation based on the interference colours was detailed by ellipsometry. The results were proved by SEM imaging on FIB cross sections and confirmed by EDS analysis in planar view. 


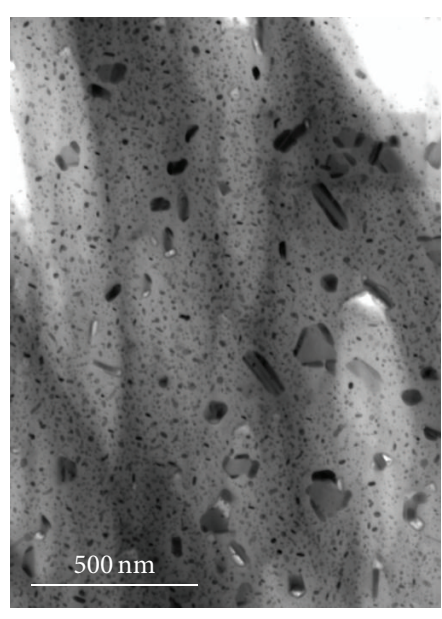

(a)

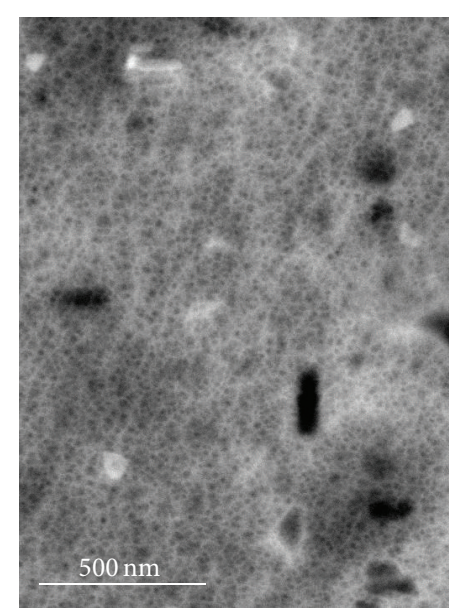

(b)

FIGURE 3: (a) LV-STEM image of IC particles in the grain interior of EN AW-7075 T73 and (b) SE image of a corresponding AAO film formed by potentiodynamic anodising of this alloy in $0.4 \mathrm{M}$ sulphuric acid showing typical pore mouths, voids caused by IC particle dissolution, and (transformed) IC particles embedded in the film.

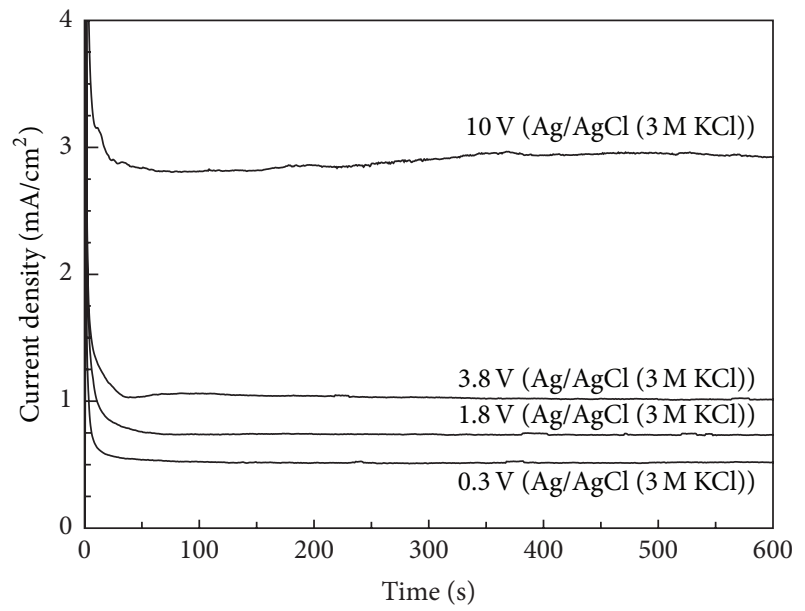

Figure 4: Current density-time behaviour during potentiostatic anodising in $0.4 \mathrm{M}$ sulphuric acid on EN AW-7075 T73 using the micro-capillary technique to form circular oxide areas $800 \mu \mathrm{m}$ in diameter.

The thickness of an anodic oxide film $(d)$ formed on pure aluminium can be estimated according to Faraday's law of electrolysis using the quantity of charge transfer at the electrode $(Q)$, the molar mass $(M)$ of the formed film, the number of electrons transferred per ion $(n)$, the Faraday constant $(F)$, and the film density $(\rho)$. Consider

$$
d=\frac{Q M}{n F \rho} .
$$

Using the charge transfer according to the averaged current densities (Figure 4) and the anodisation time of $600 \mathrm{~s}, M=$ $0.102 \mathrm{~kg} / \mathrm{mol}, n=6$ transferred electrons per reaction $\left(2 \mathrm{Al}^{3+}+3 \mathrm{O}^{2-} \rightarrow \mathrm{Al}_{2} \mathrm{O}_{3}\right)$, and $\rho=3940 \mathrm{~kg} / \mathrm{m}^{3}$ for bulk alumina, a film thickness $d_{F}$ is calculated (Table 2, column 3 ).

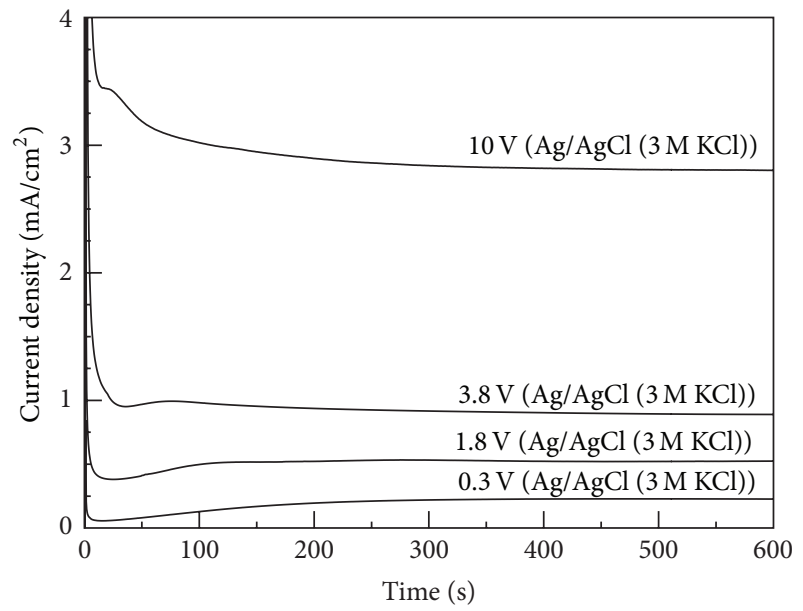

Figure 5: Current density-time behaviour during potentiostatic anodising in $0.4 \mathrm{M}$ sulphuric acid on EN AW-7075 T73 using the conventional technique to form circular areas $10 \mathrm{~mm}$ in diameter.

The figures obtained are a rough approximation. Calculated for pure aluminium, they represent the upper limit of alumina formation on one side. Otherwise, the density of the alumina film is overestimated, in particular due to the inherent pore formation in AAO films.

The interference colours of the AAO films vary from tan to blue and green under broadband incident light (Figure 6). The refractive index of alumina (corundum) is around 1.8 in the visible wavelength range which is between the corresponding refractive indices of silicon dioxide $(\sim 1.5)$ and silicon nitride $(\sim 2.0)$. Hence, it is reasonable to refer to corresponding colour/thickness charts for $\mathrm{SiO}_{2}$ and $\mathrm{Si}_{3} \mathrm{~N}_{4}$ related to microfabrication processes [26]. Accordingly, the tan colour indicates a thickness $d_{C}$ of around $50 \mathrm{~nm}$, the blue to bluish colour corresponds to values between 100 and $200 \mathrm{~nm}$, 


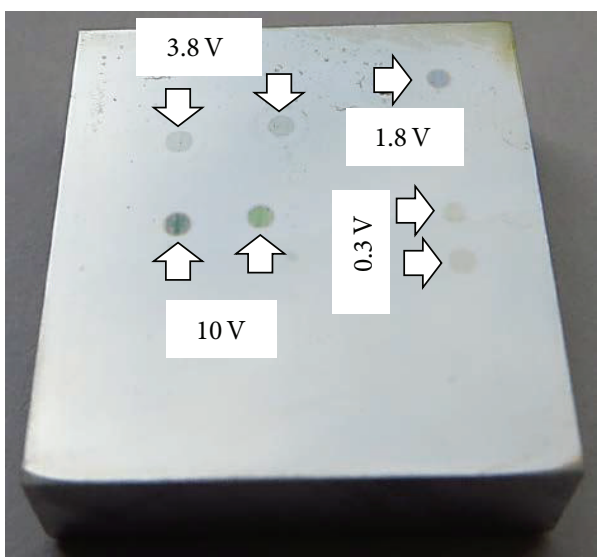

(a)

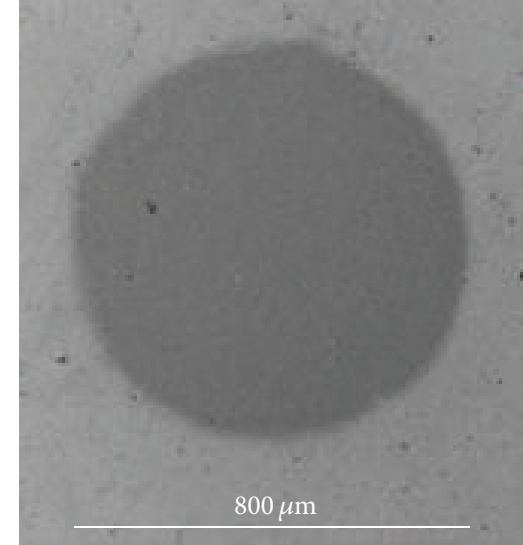

(b)

FIGURE 6: Photograph of the circular areas formed by micro-capillary anodising of EN AW-7075 T73 in the potentiostatic regime in $0.4 \mathrm{M}$ sulphuric acid at $0.3 \mathrm{~V}, 1.8 \mathrm{~V}, 3.8 \mathrm{~V}$, and $10 \mathrm{~V}$ for $600 \mathrm{~s}$ showing interference colours from tan to blue and green under broadband incident light due to their film thickness (a) and an example in SEM imaging (b).

TABLE 2: Film thickness $d_{F}$ calculated by Faraday's law (on pure Al), film thickness $d_{c}$ according to colour, film thickness $d_{E}$ estimated by ellipsometry, film thickness $d_{\text {SEM }}$ measured on cross sections (all on EN AW-7075 T73), O/Al ratio according to the film/substrate contribution calculated using the EDS spectra, and $\mathrm{O} / \mathrm{Al}$ ratio derived from EDS analysis as a function of the anodisation potential $U(\mathrm{Ag} / \mathrm{AgCl}(3 \mathrm{M} \mathrm{KCl})$ ).

\begin{tabular}{lccccccc}
\hline Film & $U(\mathrm{~V})$ & $d_{F}(\mathrm{~nm})$ & $d_{c}(\mathrm{~nm})$ & $d_{E}(\mathrm{~nm})$ & $d_{\text {SEM }}(\mathrm{nm})$ & O/Al ratio calculated & O/Al ratio measured \\
\hline 1 (Figure 7(a)) & 0.3 & 150 & $\sim 50$ & $49 \pm 15$ & $25 \pm 15$ & 0.05 & $0.08 \pm 0.05$ \\
2 (Figure 7(c)) & 1.8 & 205 & $\sim 100$ & $92 \pm 15$ & $85 \pm 20$ & 0.46 & $0.45 \pm 0.05$ \\
3 (Figure 7(e)) & 3.8 & 275 & $\sim 200$ & $165 \pm 15$ & $145 \pm 40$ & 1.12 & $1.02 \pm 0.05$ \\
4 (Figure 7(g)) & 10.0 & 745 & $\sim 500$ & $599 \pm 15$ & $590 \pm 50$ & - & $1.73 \pm 0.05$ \\
\hline
\end{tabular}

and the green colour approximates $500 \mathrm{~nm}$. Undoubtedly, the assumption of a uniform refractive index for all AAO films regardless of the anodising potential is not reliable because of differences in composition and porosity influencing their optical properties. This became apparent during the procedure of ellipsometry data analysis which iteratively converts the complex reflectance ratio as the primary data into the wavelength dependent optical constant and thickness. In the visible wave length region (i.e., $600 \mathrm{~nm}$ ), the refractive index rises from 1.65 for the thinnest film formed at $0.3 \mathrm{~V}$ to 1.9 for the other films. Correspondingly, the mean film porosity rises from $43 \%$ for films formed between $0.3 \mathrm{~V}$ and $3.8 \mathrm{~V}$ to $49 \%$ for the film formed at $10 \mathrm{~V}$; porosity gradients were not considered. The corresponding thickness $d_{E}$ derived from the iterative procedure is shown in Table 2, column 5.

For verification, cross sections located in the centre of the anodised spots were prepared by FIB. The achieved cross sections are shown in Figures 7(a), 7(c), 7(e), and 7(g). It should be noted that, prior to ion milling, the AAO films were covered by a protection layer on top. This layer is a tungsten coating which was deposited to avoid the influence of the high-energy $30 \mathrm{kV} \mathrm{Ga}$ ions. Additionally and for further characterisation of the film microstructure, the surface of the AAO films is shown in Figures 7(b), 7(d), 7(f), and 7(h). The SEM images of the cross sections reveal the thickness $d_{\mathrm{SEM}}$ (Table 2, column 6). Differences between ellipsometry and SEM values are low and suspected to originate mainly from optical anisotropy. Nevertheless, variations in the film thickness cannot be excluded because the cross sections prepared by FIB show only a limited part of the centre of the film.

EDS analysis of a $500 \times 500 \mu \mathrm{m}^{2}$ large area in planar view was used to evaluate the homogeneity of the film thickness (Figure 8). An increasing oxygen signal in the EDS spectra with increasing film thickness is expected because the excitation volume as the source of the characteristic of $\mathrm{O} K \alpha$ and $\mathrm{Al} \mathrm{K} \alpha \mathrm{X}$-rays includes the thin AAO films and the aluminium alloy below as well. Figure 8 shows to which extent film and substrate have to be considered in the case of the electron energy of $5 \mathrm{keV}$ which is for certain high enough to excite $\mathrm{Al}$ $\mathrm{K} \alpha \mathrm{X}$-rays. Considering the paths of 500 electrons using the Monte Carlo (MC) simulation method, the mean excitation depth is around $300 \mathrm{~nm}$ for aluminium oxide and aluminium, as well. The calculated depth is nearly equal for both the film and the substrate because of the opposing influences of the mean atomic number and the density of the materials giving a spherical excitation volume of $8 \mu \mathrm{m}^{3}$. This means that excitation occurs completely in the film in the case of the thickest film formed at $10 \mathrm{~V}$. The nominal $\mathrm{O} / \mathrm{Al}$ ratio of stoichiometric alumina is 1.5 , but the measured $\mathrm{O} / \mathrm{Al}$ ratio of this film is $1.73 \pm 0.05$. This is not unexpected since AAO films are known to contain additional $\mathrm{OH}$-groups at the pore walls. The $\mathrm{O} / \mathrm{Al}$ ratio is reduced due to the rising contribution of the base material to the excitation volume in the case of the thinner films. Basing on the film thickness derived from 


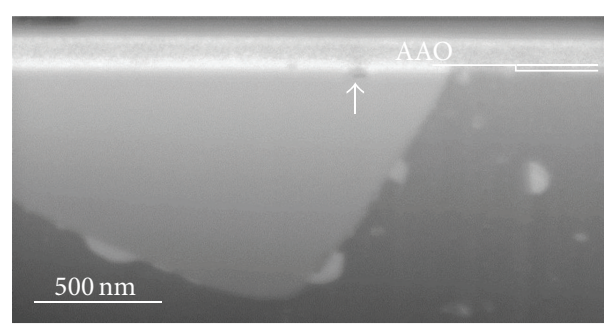

(a)

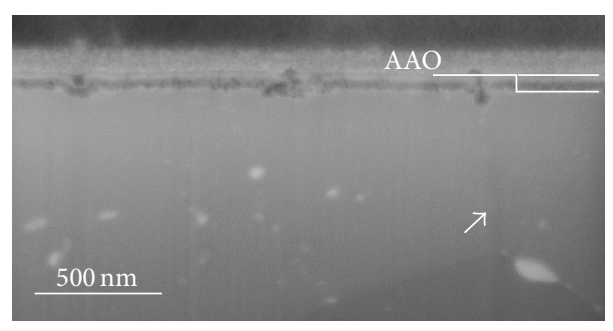

(c)

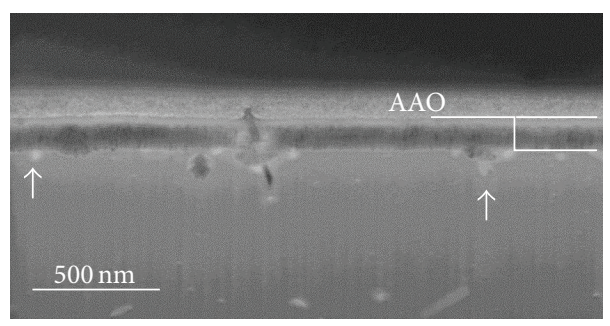

(e)

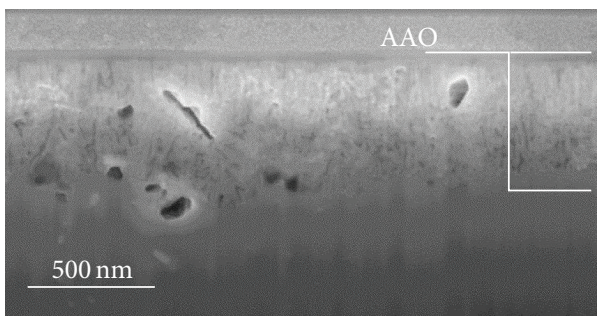

(g)

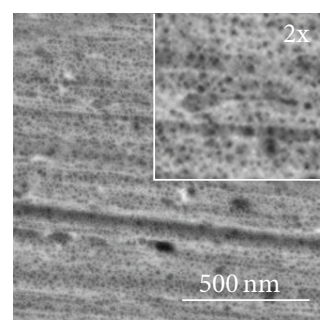

(b)

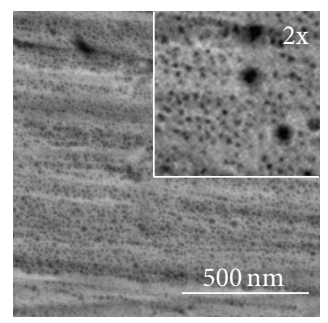

(d)

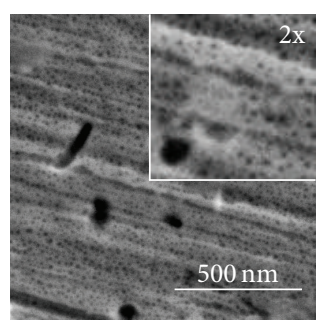

(f)

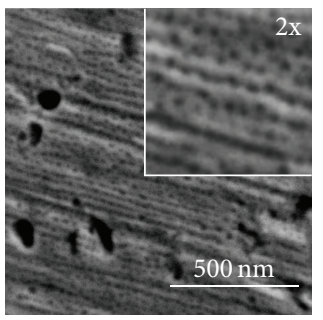

(h)

Figure 7: Cross section (left) and surface (right) of AAO films on EN AW-7075 T73 after potentiostatic anodising in 0.4 M sulphuric acid at $(\mathrm{a}, \mathrm{b}) 0.3 \mathrm{~V},(\mathrm{c}, \mathrm{d}) 1.8 \mathrm{~V},(\mathrm{e}, \mathrm{f}) 3.8 \mathrm{~V}$, and $(\mathrm{g}, \mathrm{h}) 10 \mathrm{~V}$; the AAO films are marked in the cross sections to clearly distinguish the protective coating on top (bars indicate $500 \mathrm{~nm}$ referring to identical magnification except for the twice enlarged inserts).

SEM imaging, the expected $\mathrm{O} / \mathrm{Al}$ ratios are calculated and compared to the measured values (Table 2). Apart from the thinnest film whose thickness estimation remains uncertain, a satisfactory agreement in the limits of the accuracy of the method is stated. This in turn verifies that the films of localised and conventional anodisation have a fairly uniform thickness and the values obtained from cross sections by SEM are representative for the entire film.

The correlation between the transferred charge per unit area and the film thickness on potentiostatic anodised EN AW-7075 T73 is shown in Figure 9. The results of anodising a macroscopic area at $10 \mathrm{~V}$ for durations of $1200 \mathrm{~s}$ and $3600 \mathrm{~s}$ are added to demonstrate that the results achieved by the capillary technique are comparable to anodising in a thermostatically controlled conventional process at room temperature. Macroscopic anodising at lower anodisation potentials resulted in thin films comparable to the corresponding micro-capillary AAO films. However, because of the long duration times needed for macroscopic anodisation at low anodisation potentials, preponderance of film redissolution over film formation compromised the thickness evaluation.

The main purpose of the cross section preparation was the thickness evaluation of the potentiostatic anodised films. An additional benefit is provided by revealing the behaviour of the IC particles in dependence of the applied potential for film formation which is shown exemplarily for the AAO films 


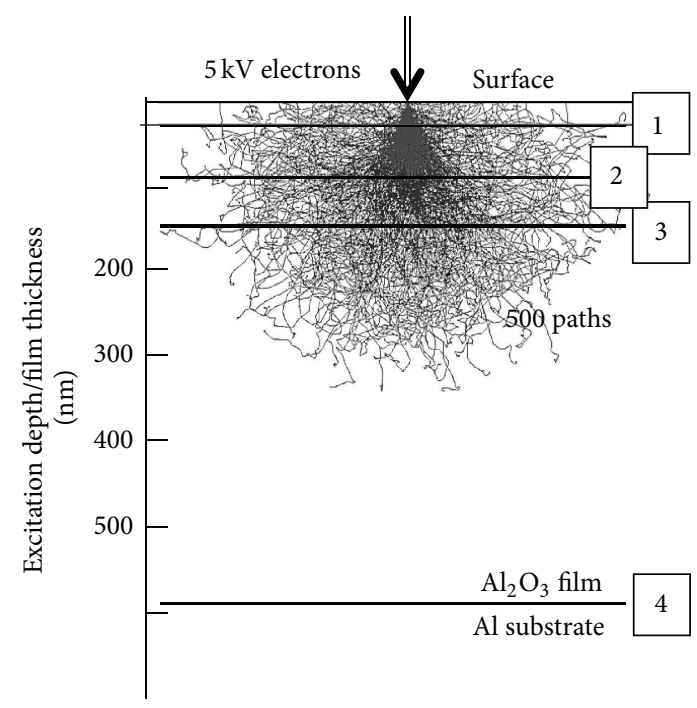

(a)

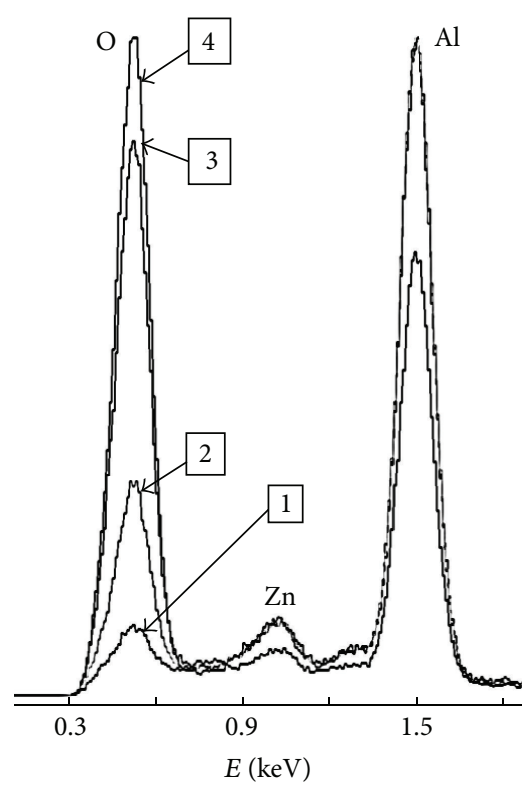

(b)

FIGURE 8: Monte Carlo simulated electron paths showing the excitation volume in the alumina films on aluminium (a) and the corresponding EDS spectra (referred to as numbered in Table 2) representing the dependence of $\mathrm{O} \mathrm{K} \alpha$ and $\mathrm{Al} \mathrm{K \alpha}$ intensities on film thickness (b).

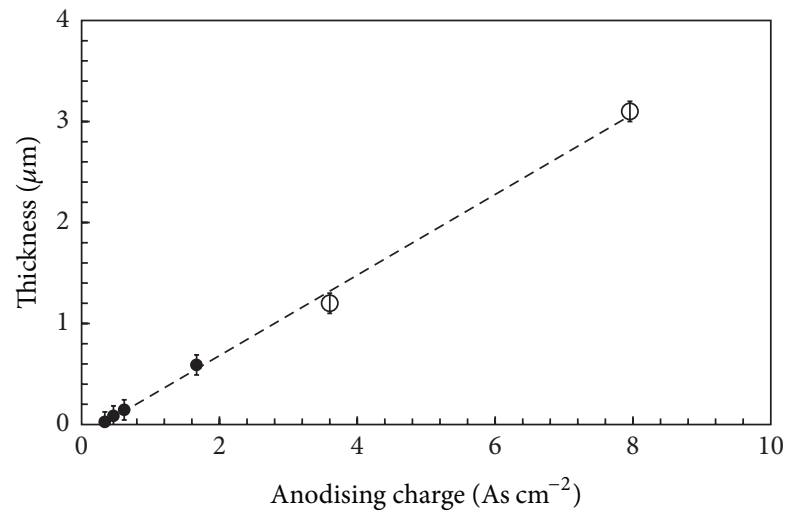

FIgURE 9: Thickness of the AAO films on EN AW-7075 T73 after potentiostatic anodising in $0.4 \mathrm{M}$ sulphuric acid formed by the micro-capillary technique at $0.3 \mathrm{~V}, 1.8 \mathrm{~V}, 3.8 \mathrm{~V}$, and $10 \mathrm{~V}$ (solid circles) for $600 \mathrm{~s}$ and by conventional anodising of circular oxide areas $10 \mathrm{~mm}$ in diameter at $10 \mathrm{~V}$ for $1200 \mathrm{~s}$ and $3600 \mathrm{~s}$ (open circles) as a function of the transferred charge per area unit.

on EN AW-7075 T73. For further characterisation of the film microstructure, the surface of the AAO films is shown in Figures $7(\mathrm{~b}), 7(\mathrm{~d}), 7(\mathrm{f})$, and $7(\mathrm{~h})$.

The AAO film formed at $0.3 \mathrm{~V}$ (Figure $7(\mathrm{a})$ ) is difficult to notice because of its low thickness. The dominating feature is a large iron-rich IC particle (most likely $\mathrm{Al}_{3} \mathrm{Fe}$ or $\mathrm{Al}_{7} \mathrm{Cu}_{2} \mathrm{Fe}$ ) in the alloy which shows a bright layer with a thickness similar to the AAO film thickness. The SE image of the surface shows shallow pores (Figure $7(\mathrm{~b})$ ).

As expected, the AAO film formed at $1.8 \mathrm{~V}$ (Figure 7(c)) is thicker and shows some voids. $\mathrm{MgZn}_{2}$ particles in the alloy are supposed to decorate the grain boundaries corresponding to the appearance in Figure 2(a). Clearly visible is a larger particle located at a high-angle grain boundary near a triple junction in the right of the figure. At the site (marked by an arrow) where the corresponding vertical grain boundary cuts the surface, the AAO film formation proceeded concurrently with the chemical dissolution of the $\mathrm{MgZn}_{2}$ phase. Similar particle dissolution that occurred simultaneously with the progress of AAO formation is observed in two other positions in the figure. At such locations, the film starts to become uneven around the developed voids. Similarly, those voids are also observed at the film surface together with a multitude of pore mouths (Figure $7(\mathrm{~d})$ ).

The AAO film formed at $3.8 \mathrm{~V}$ (Figure $7(\mathrm{e})$ ) shows progressing film thickening and dissolution of a former large rod-like particle in the centre of the image. Interestingly, not only enclosed the segment of the former particle now by the formed AAO film, but also the other half is already completely dissolved. Varying chemical behaviour of diverse IC particles can be observed. Notably, some globular second-phase particles located at the film formation front and near the rodlike void appear unaltered. They will become embedded in the AAO layer, supposedly in unchanged or transformed state if the film formation would proceed. The surface of the film reveals evidence of such embedded particles additionally to pore mouths and voids (Figure 7(f)). The pore number is slightly reduced.

The AAO film formed at $10 \mathrm{~V}$ (Figure $7(\mathrm{~g})$ ) shows all morphological features known from conversion layers of the studied alloy. Apart from voids and transformed secondphase particles, irregularities of the pore morphology can be noticed. A pronounced uneven front of film growth has been developed due to the fast dissolution of second-phase 
TABLE 3: IC particles in $\mathrm{Al}$ alloys and their behaviour during sulphuric acid anodisation.

\begin{tabular}{lcl}
\hline Phase & Evidence (this work) & Behaviour during sulphuric acid anodisation (published) \\
\hline $\mathrm{Mg}_{2} \mathrm{Si}(\beta)$ & Verified & Dissolution, cavity formation [17] \\
$\mathrm{MgZn}_{2}(\eta, \mathrm{M}, \sigma)$ & Verified & Passivation above 5 V (SCE) [25] \\
$\mathrm{Mg}_{32} \mathrm{Zn}_{49}\left(\mathrm{~T}^{\prime}\right)$ & Verified & Partial dissolution, partial oxidation [17] \\
$\mathrm{Al}_{2} \mathrm{CuMg}(\mathrm{S})$ & Verified & Preferential oxidation above 0 V (SCE) [12] \\
$\mathrm{Al}_{6} \mathrm{Mn}$ & & Partial dissolution, embedment [17] \\
$\mathrm{Al}-2 \% \mathrm{Cu}(\alpha)$ & & Yellow coating, enhanced porosity [17], copper enrichment at interface below 3 V (SCE) [9, 13] \\
$\mathrm{Al}_{2} \mathrm{Cu}(\theta)$ & Fast oxidation [17], preferential oxidation above 1.8 V (SCE) [12] \\
$\mathrm{Al}_{7} \mathrm{Cu}{ }_{2} \mathrm{Fe}$ & & Formation of Cu sponge [25], preferential oxidation above 1.8 V (SCE) [12] \\
$\mathrm{Al}_{3} \mathrm{Fe}(\beta)$ & Verified & Partial dissolution, embedment [17], preferential oxidation above 2.2 V [12] \\
$\mathrm{AlFeSi}$ phases $(\alpha)$ & & Partial dissolution, partial oxidation [17] \\
\hline
\end{tabular}

particles at the first contact with the electrolyte at the wavy interface. Branching of pores has proceeded with growing film thickness. Pore mouths at the surface are remarkably reduced in number and enhanced in diameter (Figure $7(\mathrm{~h})$ ).

\section{Discussion}

The pronounced peaks in the polarisation curve during potentiodynamic anodising (Figure 1) are associated with the oxidation and dissolution of IC particles in the aluminium alloys. Conventional "macro-area" anodising studies by Saenz de Miera et al. [12] and Curioni et al. [13] reveal similar potentiodynamic behaviour. This can be stated for all studied alloys but is particularly obvious in the case of EN AW-2024. According to [13], the striking peak around $0 \mathrm{~V}$ (SCE) is expected for EN AW-2024 and EN AW-7075 attributed to the S-phase $\left(\mathrm{Al}_{2} \mathrm{CuMg}\right)$ with the peak intensity indicating the higher concentration in EN AW-2024.

Similarly shown for high purity aluminium in conventional experiments [12], no peaks appear in the curves of the micro-capillary cell experiment of Al $5 \mathrm{~N}$ and EN AW1050 due to the absence of copper-containing second-phase particles. The thickening of the natural oxide on aluminium starts around $0.35 \mathrm{~V}$ (SCE) [12] and the following region of monotone current rise is connected with further oxide formation and film thickening.

According to the results of Keller et al. [6] and O'Sullivan and Wood [27], the thickness of the barrier layer and the diameter of the pores theoretically extend from 0.5 to $12 \mathrm{~nm}$ with rising anodising potential from 0.3 to $10 \mathrm{~V}$. Correspondingly, the cell diameter enhances from 0.6 to $22 \mathrm{~nm}$. Although these findings relate to pure aluminium, a qualitatively similar behaviour is observed for the pore and cell dimensions of the alloy EN AW-7075 T73 (Figures 7(b), 7(d), 7(f), and 7(h)). Corresponding to the pore and cell sizes in pure aluminium, the calculated pore volume decreases from $55 \%$ to $23 \%$ [27]. In practice, pore volume is generally greater than calculated because dissolution occurs at inner and outer surfaces of the coating during the time of anodisation. Additionally, the porosity in alloys is enhanced by voids formed due to the IC particle dissolution. Therefore considering the rising quantity of IC particles which underwent dissolution and leave additional voids in the film, porosity values between $43 \%$ and $49 \%$ derived from the ellipsometry study are sound and support the thickness results of ellipsometry.

The correlation between the transferred charge and the film thickness is similar comparing the results of microcapillary anodising in a stagnant electrolyte and of macroscopic anodising in a thermostatically controlled and agitated electrolyte (Figure 9). A rise in temperature during the micro-capillary process might be expected due to the heat released above the spots inside the capillary. However, the transferred charge remains very low because of the small area to be anodised and the small duration (600 s) consequently needed. Nevertheless, parameter control by temperature stabilisation and composition balance of the electrolyte has to be kept in view for further development.

The anodising behaviour of second-phase particles was reviewed by Jelinek [17]. Recent detailed studies were published by Paez et al. [9], Saenz de Miera et al. [12, 14], Curioni et al. [13], and Tardelli and Rocca [25]. The phases with relevance to the studied alloys are listed in Table 3. Their verification by EDS on electron transparent samples of the alloy we focused on in this work is also indicated in the table. Although the micro-capillary cell technique has been applied for corrosion studies either on synthesised analogues of intermetallic compounds by Birbilis and Buchheit [22] modelling the second phases present in aluminium alloys or on a 7075 alloy in solution heat-treated condition and in T6 temper by Andreatta et al. [21], the applicability for local anodising was missing even after several modifications in the technical equipment. As presented for corrosion studies $[21,22]$, single precipitates could not be examined, but their galvanic coupling revealed changes from anodic to cathodic behaviour with respect to the temper state of the alloy matrix. Comparing our local results of anodising with the dissolution behaviour in chloride containing medium by Cavanaugh et al. [28] and Wloka and Virtanen [29], for example, similar behaviour can be stated. Cavanaugh et al. found anodic behaviour of the phases $\mathrm{MgZn}_{2}$ and $\mathrm{Mg}_{2} \mathrm{Si}$ and cathodic behaviour of the phases $\mathrm{Al}_{7} \mathrm{Cu}_{2} \mathrm{Fe}, \mathrm{Al}_{3} \mathrm{Fe}$, and $\mathrm{Al}_{2} \mathrm{CuMg}$ with respect to the matrix of AA7075 $\mathrm{T} 6$.

Wloka and Virtanen [29] confirmed anodic behaviour of $\mathrm{MgZn}_{2}$ and cathodic behaviour of $\alpha-\mathrm{Al}_{7} \mathrm{Cu}_{2} \mathrm{Fe}$ with respect to the matrix and evidenced that $\mathrm{MgZn}_{2}$ is first dissolved due the high dissolution rate. $\mathrm{Mg}_{2} \mathrm{Si}$ undergoes a selective dissolution 


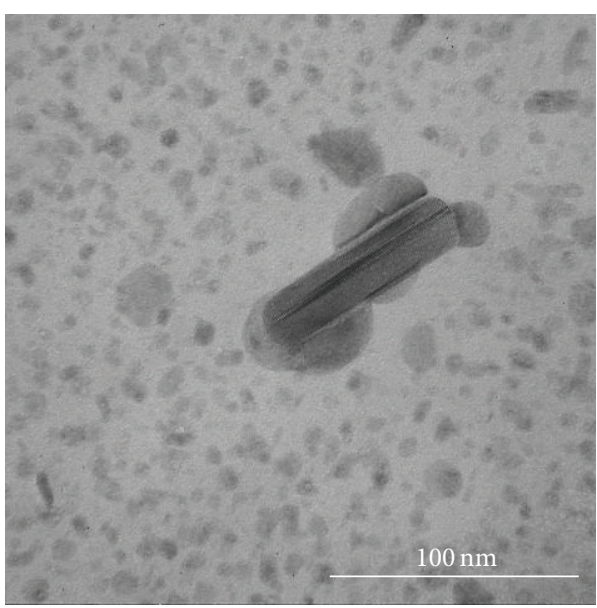

(a)

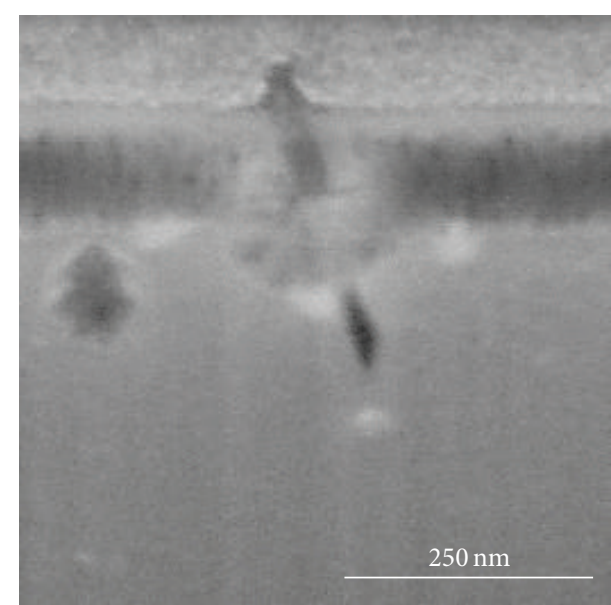

(b)

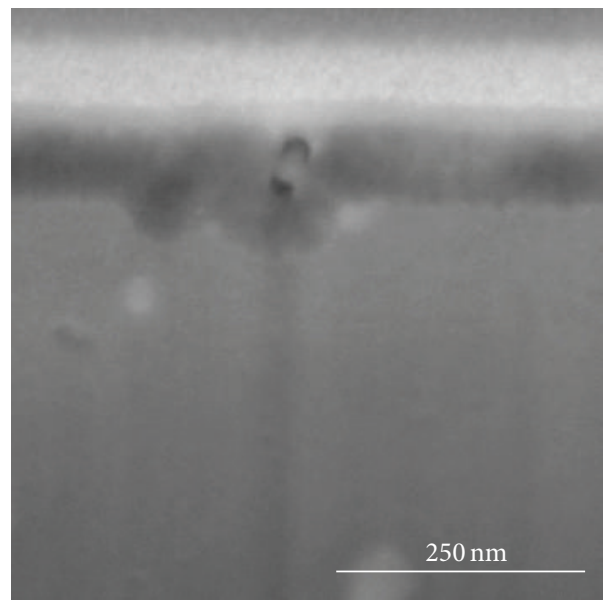

(c)

FIgure 10: Comparison of a (a) coarsened $\mathrm{MgZn}_{2}$ particle ( $\eta$-phase) surrounded by $\mathrm{Mg}_{2} \mathrm{Si}$ or $\mathrm{Mg}_{32} \mathrm{Zn}_{49}$ particles in the alloy EN AW7075 with the corresponding appearance in the AAO film on that alloy after anodisation at $3.8 \mathrm{~V}$ showing (b) dissolution of $\mathrm{MgZn}_{2}$ and (c) transformation of $\mathrm{Mg}_{2} \mathrm{Si}$ to $\mathrm{SiO}_{x}$.

of $\mathrm{Mg}$ leaving $\mathrm{SiO}_{x}$ particles behind; oxygen reduction takes place at the cathodic $\mathrm{Al}_{7} \mathrm{Cu}_{2} \mathrm{Fe}$ phase with pitting corrosion of the matrix. The behaviour of the second phases during anodisation in sulphuric acid shows similarities. Tardelli and Rocca [25] anodised model phases in sulphuric acid and evidenced selective dissolution of $\mathrm{Al}_{7} \mathrm{Cu}_{2} \mathrm{Fe}$ accompanied by formation of a nanometric sponge of copper at the surface. Bulk $\mathrm{MgZn}_{2}$ formed an oxidic passivation layer above $5 \mathrm{~V}$ (SCE) with a high redissolution rate. Saenz de Miera et al. [12, 14] prepared intermetallic compound layers as macroscopic model specimens. The oxidation of the S-phase $\left(\mathrm{Al}_{2} \mathrm{CuMg}\right)$ was found to start around $0 \mathrm{~V}$ (SCE) with the magnesium hindering the formation of a stable oxide. Oxidation of copper and iron containing particles like $\mathrm{Al}_{7} \mathrm{Cu}_{2} \mathrm{Fe}$ started above $2 \mathrm{~V}$ (SCE), but at reduced rate. Depending on their initial size, corresponding particles were suspected to be partially or completely oxidised supporting a relatively stable oxide [12]. We found a thin metallic film formation on the large constituent phase (apparently $\mathrm{Al}_{7} \mathrm{Cu}_{2} \mathrm{Fe}$ ) after anodisation at
$0.3 \mathrm{~V}$ which is correlated to the selective dissolution found by Tardelli and Rocca [25]. We observed fast and complete dissolution of $\mathrm{MgZn}_{2}$ particles resulting in voids of corresponding shape in agreement with Tardelli and Rocca [25] and Cavanaugh et al. [28]. Transformed particles embedded in the AAO film are supposed to be mainly $\mathrm{SiO}_{x}$ as a result of selective $\mathrm{Mg}$ dissolution of $\mathrm{Mg}_{2}$ Si particles [17, 22, 28].

To illustrate this, $\mathrm{MgZn}_{2}$ particles coarsened by overaging and surrounded by $\mathrm{Mg}_{2} \mathrm{Si}$ or $\mathrm{Mg}_{32} \mathrm{Zn}_{49}$ particles were studied before and after anodisation by TEM and SEM imaging, respectively (Figure 10). The behaviour of the IC particles and their influence on the morphology of the anodised film is shown on the cross section after FIB milling (Figures 10(b) and 10(c)). Because of the combination of milling and imaging, the SE image quality is influenced by the compromises concerning the sample position with respect to the objective lens and moreover limited due to the beam sensitivity of the $\mathrm{AAO}$ film and the residual curtaining left after preparation. However, in contrast to metallographic preparation of cross 
sections, ion beam milling provides more detail concerning embedded particles inside of voids. Such particles regularly disappear during the grinding and polishing processes for sample preparation as can be seen in Figure 2(d). The TEM image in Figure 10 (a) shows a coarse $\mathrm{MgZn}_{2}$ particle with surrounding $\mathrm{Mg}_{2} \mathrm{Si}$ or $\mathrm{Mg}_{32} \mathrm{Zn}_{49}$ particles in the alloy. The shape of a corresponding void in the oxide film after particle dissolution is evidenced in Figure 10(b), a magnified detail of Figure $7(\mathrm{e})$. The void is surrounded by relatively stable particles which seem to get anodised or transformed and embedded in the film (Figure 10(c)). This appears to be fairly similar to the behaviour of the IC particles observed under corrosive attack [28].

The microscopic study of the cross sections combined the study of the oxide morphology with the microstructure of the alloy below the formed AAO film. As a result of the presented work, above $1.8 \mathrm{~V}$ the dissolution of the hardening phase in EN AW-7075 T73 during anodisation produces a coating with numerous voids of the size of the IC particles and moreover with local thickness variations due to the dissolution of these microstructural constituents at the anodisation frontier.

One advantage of the used method is that electrochemistry and microstructure of the IC particles contained in the alloy and transformed by anodising can be studied correspondingly. Unfortunately, the micro-capillary method cannot offer the possibility to size down the anodised area to the size of single secondary particles. Using a potential minimal capillary diameter around $15 \mu \mathrm{m}$ would at least enable the study of small areas with different phases side by side. The smaller the diameter of the capillary the more necessary a continuous exchange of the electrolyte to avoid alteration and to control temperature. This requires a continuous electrolyte flow in the micro-capillary cell as already presented for a multi-scanning droplet cell presented in [30] used as example for anodising titanium between 11 and $18 \mathrm{~V}$.

\section{Conclusions}

The successful development of electrolyte formulations for anodising of aluminium alloys and aluminium matrix composites requires measurement of electrochemical parameters, thickness monitoring, and visualising the formation of the film and the transformation of the containing IC particles. Using conventional anodising for this task necessitates the application of large electrolyte volumes in the scale of several litres with the drawback of high expenses for procurement and disposal.

The micro-capillary technique provides an advantageous approach for a more efficient investigation of the anodising process. The influence of the electrolyte composition and anodisation regime on the electrochemical response of alloys with different composition and condition can be investigated by applying low electrolyte volumes and short anodisation durations at small areas. Methods of film evaluation (thickness, microstructure, and morphology) were adapted to the anodised spots of limited thickness (i.e., below $1 \mu \mathrm{m}$ ) and area (i.e., $0.5 \mathrm{~mm}^{2}$ ). This was accomplished by using ellipsometry, energy dispersive X-ray analysis, and preparation of cross sections by focused ion beam milling and exemplarily shown for
AlZn5.5MgCu. Thus, the method provides an efficient tool to study different electrolyte formulations. Additionally, insights into film formation and transformation of IC particles are provided by the applied techniques and can be extended to study particle strengthened aluminium matrix composites.

A comparison of the behaviour of the studied alloy during conventional anodising with a large circulated electrolyte volume at controlled temperature demonstrated the general utility and the limitations of the micro-capillary method. Further work will include the improvement of the microcell setup. In particular, a continuous electrolyte flow should be provided to avoid electrolyte alteration and heating.

\section{Conflict of Interests}

The authors declare that there is no conflict of interests regarding the publication of this paper.

\section{Acknowledgments}

Financial support was granted by Deutsche Forschungsgemeinschaft (German Research Foundation) in the collaborative research centre "High-Strength Aluminium-Based Lightweight Materials for Safety Components" (DFG SFB 692) and in the cluster of excellence "MERGE Technologies for Multifunctional Lightweight Structures" (DFG EXC 1075). The authors wish to thank Peter Richter and Professor D. R. T. Zahn, Semiconductor Physics, TU Chemnitz, for providing ellipsometry measurements and analyses. TEM preparation and study of the alloy were performed by Anne Schulze, Materials Engineering Group, TU Chemnitz. Thanks to Dagobert Spieler, Materials and Surface Engineering Group, TU Chemnitz, comprehensive electrochemical measurements, careful anodisation, and competent service of the microcell equipment have been accomplished.

\section{References}

[1] R. Ayer, J. Y. Koo, J. W. Steeds, and B. K. Park, "Microanalytical study of the heterogeneous phases in commercial Al- $\mathrm{Zn}-\mathrm{Mg}$ Cu alloys," Metallurgical Transactions A, vol. 16, no. 11, pp. 19251936, 1985.

[2] S. T. Lim, I. S. Eun, and S. W. Nam, "Control of equilibrium phases (M,T,S) in the modified aluminum alloy 7175 for thick forging applications," Materials Transactions, vol. 44, no. 1, pp. 181-187, 2003.

[3] D. J. Lloyd and M. C. Chaturvedi, "A calorimetric study of aluminium alloy AA-7075," Journal of Materials Science, vol. 17, no. 6, pp. 1819-1824, 1982.

[4] J. K. Park and A. J. Ardell, "Microstructures of the commercial $7075 \mathrm{Al}$ alloy in the T651 and T7 tempers," Metallurgical Transactions A, vol. 14, no. 10, pp. 1957-1965, 1983.

[5] P. G. Sheasby and R. Pinner, The Surface Treatment and Finishing of Aluminum and Its Alloys, vol. 2, ASM International, Materials Park, Ohio, USA, 2001.

[6] F. Keller, M. S. Hunter, and D. L. Robinson, "Structural features of oxide coatings on aluminum," Journal of the Electrochemical Society, vol. 100, no. 9, pp. 411-419, 1953. 
[7] G. E. Thompson, H. Habazaki, K. Shimizu et al., "Anodizing of aluminium alloys," Aircraft Engineering and Aerospace Technology, vol. 71, no. 3, pp. 228-238, 1999.

[8] D. Nickel, T. Lampke, G. Alisch, and S. Steinhäuser, "Microstructural effect on the wear behaviour of the hard-anodised aluminium alloys EN AW-6082 and EN AW-7075," Materialwissenschaft und Werkstofftechnik, vol. 40, no. 7, pp. 523-531, 2009.

[9] M. A. Paez, O. Bustos, G. E. Thompson, P. Skeldon, K. Shimizu, and G. C. Wood, "Porous anodic film formation on an Al-3.5 wt \% Cu alloy," Journal of the Electrochemical Society, vol. 147, no. 3, pp. 1015-1020, 2000.

[10] S. Feliu Jr., M. J. Bartolomé, J. A. González, V. López, and S. Feliu, "Passivating oxide film and growing characteristics of anodic coatings on aluminium alloys," Applied Surface Science, vol. 254, no. 9, pp. 2755-2762, 2008.

[11] Y.-S. Huang, T.-S. Shih, and J.-H. Chou, "Electrochemical behavior of anodized AA7075-T73 alloys as affected by the matrix structure," Applied Surface Science, vol. 283, pp. 249-257, 2013.

[12] M. Saenz de Miera, M. Curioni, P. Skeldon, and G. E. Thompson, "Modelling the anodizing behaviour of aluminium alloys in sulphuric acid through alloy analogues," Corrosion Science, vol. 50, no. 12, pp. 3410-3415, 2008.

[13] M. Curioni, M. Saenz de Miera, P. Skeldon, G. E. Thompson, and J. Ferguson, "Macroscopic and local filming behavior of AA2024 T3 aluminum alloy during anodizing in sulfuric acid electrolyte," Journal of the Electrochemical Society, vol. 155, no. 8, pp. C387-C395, 2008.

[14] M. Saenz de Miera, M. Curioni, P. Skeldon, and G. E. Thompson, "The behaviour of second phase particles during anodizing of aluminium alloys," Corrosion Science, vol. 52, no. 7, pp. 24892497, 2010.

[15] D. Dietrich, S. Nehrkorn, M. Händel et al., "A hardness-microstructure correlation study of anodised powder-metallurgical $\mathrm{Al}-\mathrm{Cu}$ alloy composites," Surface and Coatings Technology, vol. 242, pp. 118-124, 2014.

[16] R. Morgenstern, D. Nickel, D. Dietrich, I. Scharf, and T. Lampke, "Anodic oxidation of AMCs: influence of process parameters on coating formation," Materials Science Forum, vol. 825-826, pp. 636-644, 2015.

[17] T. W. Jelinek, Oberflächenbehandlung von Aluminium, Eugen G. Leuze, Saulgau, Germany, 1997.

[18] M. Curioni, T. Gionfini, A. Vicenzo, P. Skeldon, and G. E. Thompson, "Optimization of anodizing cycles for enhanced performance," Surface and Interface Analysis, vol. 45, no. 10, pp. 1485-1489, 2013.

[19] H. Böhni, T. Suter, and A. Schreyer, "Micro- and nanotechniques to study localized corrosion," Electrochimica Acta, vol. 40, no. 10, pp. 1361-1368, 1995.

[20] M. M. Lohrengel, "Electrochemical capillary cells," Corrosion Engineering Science and Technology, vol. 39, no. 1, pp. 53-58, 2004.

[21] F. Andreatta, M. M. Lohrengel, H. Terryn, and J. H. W. de Wit, "Electrochemical characterisation of aluminium AA7075T6 and solution heat treated AA7075 using a micro-capillary cell," Electrochimica Acta, vol. 48, no. 20-22, pp. 3239-3247, 2003.

[22] N. Birbilis and R. G. Buchheit, "Electrochemical characteristics of intermetallic phases in aluminum alloys-an experimental survey and discussion," Journal of the Electrochemical Society, vol. 152, no. 4, pp. B140-B151, 2005.
[23] T. Suter and H. Böhni, "A new microelectrochemical method to study pit initiation on stainless steels," Electrochimica Acta, vol. 42, no. 20-22, pp. 3275-3280, 1997.

[24] J. P. Kollender, M. Voith, S. Schneiderbauer, A. I. Mardare, and A. W. Hassel, "Highly customisable scanning droplet cell microscopes using 3D-printing," Journal of Electroanalytical Chemistry, vol. 740, pp. 53-60, 2015.

[25] J. Tardelli and E. Rocca, "Electrochemical behaviour of intermetallic phases in sulfuric acid at high voltage-anodization of $\mathrm{Al}_{7} \mathrm{Cu}_{2} \mathrm{Fe}$ and $\mathrm{MgZn}_{2}$ phase," http://sites.poli.usp.br/org/ emcr2012/CD/PDF/Oral\%2026_Rocca.pdf.

[26] J. Henrie, S. Kellis, S. M. Schultz, and A. Hawkins, "Electronic color charts for dielectric films on silicon," Optics Express, vol. 12, no. 7, pp. 1464-1469, 2004.

[27] J. P. O'Sullivan and G. C. Wood, "The morphology and mechanism of formation of porous anodic films on aluminium," Proceedings of the Royal Society of London Series A: Mathematical and Physical Sciences, vol. 317, no. 1, pp. 511-543, 1970.

[28] M. K. Cavanaugh, R. G. Buchheit, and N. Birbilis, "Evaluation of a simple microstructural-electrochemical model for corrosion damage accumulation in microstructurally complex aluminum alloys," Engineering Fracture Mechanics, vol. 76, no. 5, pp. 641650, 2009.

[29] J. Wloka and S. Virtanen, "Detection of nanoscale $\eta$-MgZn2 phase dissolution from an $\mathrm{Al}-\mathrm{Zn}-\mathrm{Mg}-\mathrm{Cu}$ alloy by electrochemical microtransients," Surface and Interface Analysis, vol. 40, no. 8, pp. 1219-1225, 2008.

[30] J. P. Kollender, A. I. Mardare, and A. W. Hassel, "Multi-Scanning Droplet Cell Microscopy (multi-SDCM) for truly parallel high throughput electrochemical experimentation," Electrochimica Acta, vol. 179, pp. 32-37, 2015. 

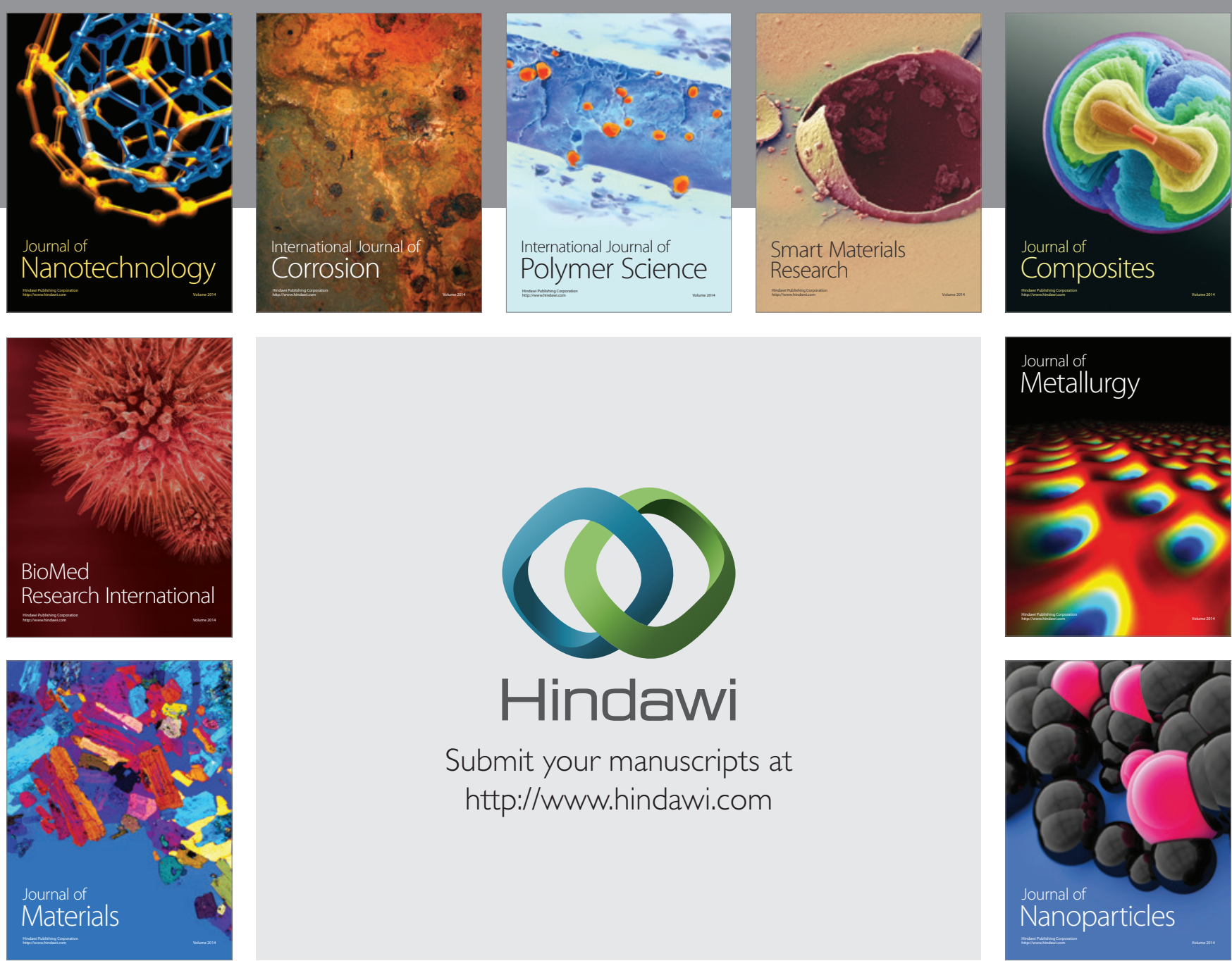

\section{Hindawi}

Submit your manuscripts at

http://www.hindawi.com

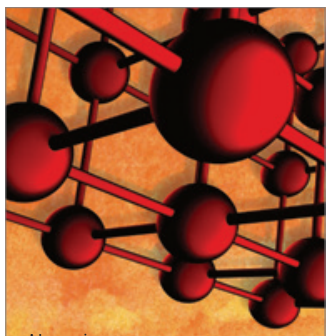

Materials Science and Engineering
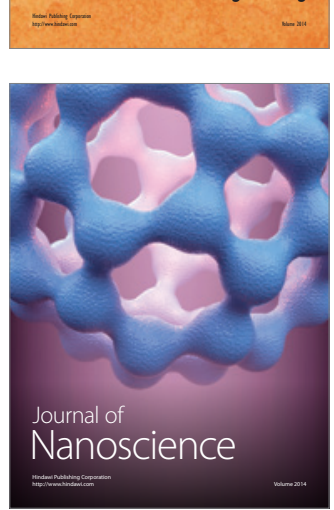
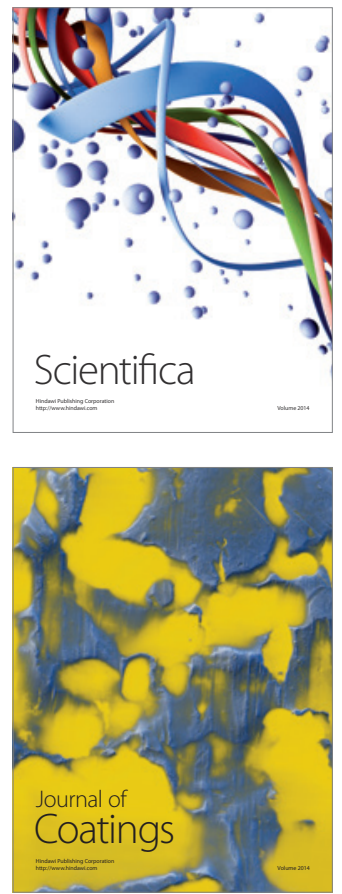
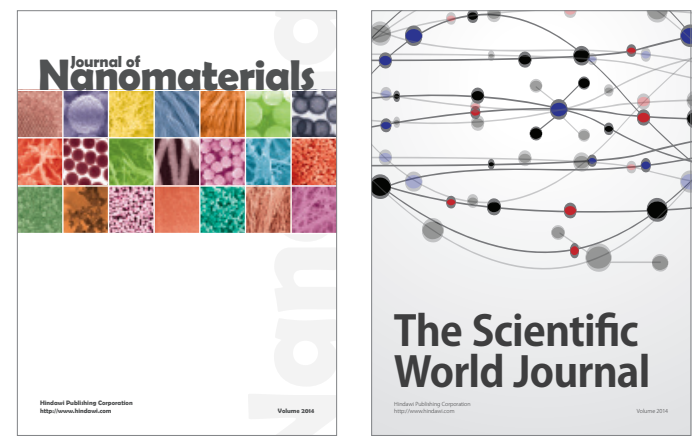

The Scientific World Journal
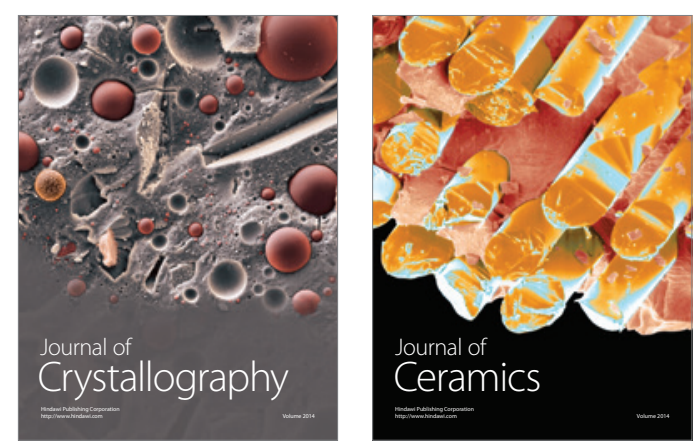
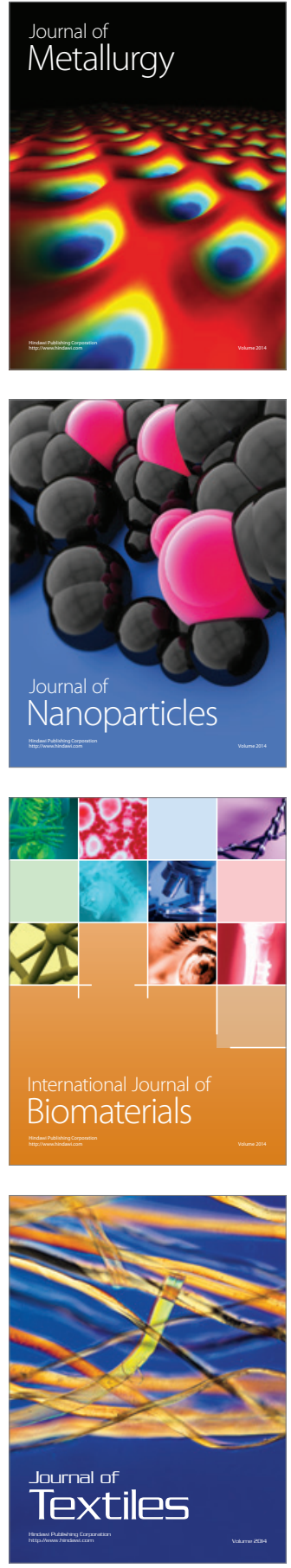